\title{
Comparison of Musical Expression of Distinguished and Unnamed Pianists in Tonal Tension and Attraction Models
}

\author{
Tetsuya Mizutani ${ }^{1, *}$, Shota Nakahara ${ }^{2}$ and Takuya Takeda ${ }^{2}$ \\ ${ }^{1}$ Department of Information Engineering, University of Tsukuba, Ibaraki 3058573, JAPAN \\ ${ }^{2}$ College of Information Science, University of Tsukuba, Ibaraki 3058573, JAPAN \\ ${ }^{*}$ Corresponding author
}

\begin{abstract}
Musical expression of piano performances by some distinguished pianists has been analyzed by the authors. In the analysis, the tonal tension and attraction models have been used, those are introduced in the literature of the generative theory of tonal music named "Tonal Pitch Spaces" by F. Lerdal. From the analysis, some specific features of their musical expression have been obtained. In this article, performances by "unnamed" pianists are analyzed in the same models and compared them to those by the distinguished pianists. By the analyses, the results are obtained, e.g. the difference between the musical expression by the distinguished pianists and that by unnamed pianists is very definite.
\end{abstract}

Keywords-musical expression; tonal music theory; tonal tension; tonal attraction; multiple regression analysis

\section{INTRODUCTION}

Musical expression is constructed from repetition of relaxation and tension. They are also affected by some kinds of attraction between each adjacent pairs of events, i.e. each group of notes sounding simultaneously that forms a chord. The tension in a score is made from its chord progression, melodic motion, melodic progression, beat structure, rhythmic structure, etc., while the attraction between two adjacent notes is made from stability of these pitches in a chord.

A generative theory of tonal music (GTTM) [1] is a cognitive theory of tonal music that analyzes music by some strong hypotheses and structural rules of music, and that introduces the hierarchical musical structures. Tonal pitch space (TPS) [2] is a succession of the theory that introduces structures of pitch, tone, chord, etc. It also introduces the tonal tension structure of chord progression, by which the tension value is defined. Moreover, the melodic attraction is also introduced by TPS for each pair of pitches indicating how stable, or natural, when a note of some pitch is performed after the other note of another pitch. The attraction value for each adjacent pair of pitches is defined as some kind of ratio between these strength values.

The relationship between the harmonic tension with the melodic attraction values and musical expression, i.e. the change of tempo and volume, of the actual performances of piano by some distinguished pianists has been analyzed in $[3,4,5]$ in the models by the multiple regression analysis. These analyses show that the tension and attraction affect musical expression significantly.

In this article, as reported in [6], musical expression of some performances by unnamed, i.e. amateur or semi-professional pianists are analyzed and evaluated in the same models and methods, and these two groups of expression are compared with each other. From the evaluation, some features are obtained, e.g. the musical expression of tempo played by distinguished pianists are affected by a certain kind of expression marks for volume, such as crescendo and decrescendo, whereas those by unnamed pianists are not.

\section{HARMONIC TENSION AND MELODIC ATtRACTION}

In this section, the harmonic tension and melodic attraction are briefly explained along [5].

\section{A. Harmonic Tension Value}

The chord distance between two chords expresses the distance of them in the musical theory.

Definition 1. The chord distance $\delta(x \rightarrow y)$ between two chords $x$ and $y$ is defined as

$$
\delta(x \rightarrow y)=i+j+k,
$$

where $i$ is the distance in the cycle of fifth of the diatonic scale of $x$ and that of $y ; j$ the distance of two chords in the cycle of fifth; $k$ the weighted sum of $y$ minus that of $x$. The weighted sum of a chord is calculated as the following weight for each note in the chord: weight 4 if it is the root note, 3 if the fifth note in the chord, 1 if the other note in the chord, and 0 otherwise, i.e. it does not consist of the chord.

The harmonic tension value for each chord in the music score is defined by the prolongational tree and the chord distance, where the former expresses the hierarchical relationship between each harmonic and melodic event from musical score, and it represents the repetition of tension and relaxation, and that of continuity and progression.

Definition 2. The surface tension value $T_{\text {diss }}(y)$ for a target chord y is defined as 


$$
T_{\text {diss }}(y)=s d+i n v+n t,
$$

where $s d$ (scale degree) is 1 if the melodic note is the third or the fifth of $y$ and 0 otherwise; inv (inversion) 2 if it is inversion, and 0 otherwise; $n t$ (nonharmonic tone) 1 for seventh, 3 for diatonic nonharmonic, 4 for chromatic nonharmonic tone and 0 otherwise.

Definition 3. The hierarchical global tension value $T_{\text {glob }}(y)$ for a chord y is defined as

$$
T_{\text {glob }}(y)=T_{\text {diss }}(y)+\delta\left(x_{\text {dom }} \rightarrow y\right)+T_{\text {inh }}\left(x_{\text {dom }}\right),
$$

where $y$ is the target chord; $x_{\text {dom }}$ the chord that directly dominates $y$ in the prolongational tree; $T_{\text {diss }}(y)$ the surface tension associated with y; $\delta\left(x_{d o m} \rightarrow y\right)$ the chord distance from $x_{\text {dom }}$ to $y ; T_{i n h}\left(x_{\text {dom }}\right)$, called the inheritance tension value of $y$, defined as the sum of the distance values inherited by $y$ from chords that dominate $x_{\text {dom }}$.

\section{B. Melodic Attraction Values}

Definition 4. The anchoring strength is defined for each pitch in the context of chord as follows: value 4 if the pitch is root note in the chord, 3 if the third or the fifth, 2 if it is other pitch belonging in the chord and 1 otherwise, i.e. it does not consist of the chord.

Definition 5. The melodic attraction $\alpha\left(p_{1} \rightarrow p_{2}\right)$ for a pitch $p_{1}$ to another $p_{2}$ with $p_{1} \neq p_{2}$ is defined as

$$
\alpha\left(p_{1} \rightarrow p_{2}\right)=\frac{s_{2}}{s_{1}} \times \frac{1}{n^{2}}
$$

where $s_{1}$ and $s_{2}$ are the anchoring strength of $p_{1}$ and $p_{2}$, respectively, and $n$ is the number of semitone interval between $p_{1}$ and $p_{2}$.

Definition 6. The realized voice-leading attraction $\alpha_{r v l}\left(C_{1} \rightarrow C_{2}\right)$ for a chord $C_{1}$ to another chord $C_{2}$ such that not all pitches are identical is defined as:

$$
\alpha_{r v l}\left(C_{1} \rightarrow C_{2}\right)=\alpha_{r 1}+\cdots+\alpha_{r n},
$$

where $\alpha_{r 1}, \ldots, \alpha_{r n}$ are the melodic attractions for all the voices in $C_{1}$ to $C_{2}$.

\section{Multiple Regression Analysis}

The multiple regression analysis [7] is a statistical technique for estimating the relationships among a dependent variable and some independent variables.

Let $y$ be a dependent variable, $x_{1}, \ldots, x_{n}$ be independent variables, $a_{1}, \ldots, a_{n}$ be partial regression coefficients, and $a_{0}$ be an intercept. Suppose that the sample size is greater than $n$. Then, the optimum solution for the coefficients is obtained by the least square method from the multiple regression functions

$$
y=a_{0}+a_{1} x_{1}+\cdots+a_{n} x_{n}
$$

The p-value indicates the probability that the partial regression coefficient is 0 . In general, it is the strong evidence against null hypothesis, i.e. the coefficient is meaningful, if the value is less than 0.05 , when the significant level is $5 \%$.

\section{DATA USED IN THE EXPERIMENTS}

\section{A. Dependent and Independent Variables}

The samples used in the analyses are events in a score, each of which is the set of notes sounding simultaneously. The value of the dependent variable is local tempo or volume of the corresponding event, each of which is calculated individually. The values of independent variables are hierarchical global tension and the realized voice-leading attraction values of each event, whose values are nonnegative integers, and additionally, the existence of each expression marks, e.g. accent, crescendo, etc., whose values are 1 if exists and 0 otherwise.

\section{B. Musical Data}

Score and performance data used in this article are obtained from CrestMusePEDB [8] providing by the CrestMuse Project. The titles of the music pieces and the composers with the number of data played by distinguished and unnamed pianists are shown in Table 1. From here, the group of distinguished pianists is called $D$, and that of unnamed pianists is $U$.

TABLE I. MUSICAL DATA USED IN THE EXPERIMENTS

\begin{tabular}{|l|c|c|}
\hline \multirow{2}{*}{$\begin{array}{l}\text { Music Title } \\
\text { (Composer) }\end{array}$} & \multicolumn{2}{|c|}{ Data Number } \\
\cline { 2 - 3 } & $\begin{array}{c}\text { Distinguished } \\
\text { Pianists }\end{array}$ & $\begin{array}{c}\text { Un- } \\
\text { named } \\
\text { Pianists }\end{array}$ \\
\hline $\begin{array}{l}\text { Piano Sonata No. 11 in A major, K. 331 } \\
\text { (W. A. Mozart) }\end{array}$ & 8 & 33 \\
\hline $\begin{array}{l}\text { Piano Sonata No. 8 in C minor, Op. 13, } \\
\text { "Sonata Pathétique" } \\
\text { (L. v. Beethoven) }\end{array}$ & 3 & 32 \\
\hline $\begin{array}{l}\text { Kinderscenen, Op. 15, No. 7, in F major, } \\
\text { "Träumerei” } \\
\text { (R. A. Schumann) }\end{array}$ & 2 & 1 \\
\hline $\begin{array}{l}\text { Étude Op. 10, No. 3, in E major } \\
\text { (F. F. Chopin) }\end{array}$ & 1 & \\
\hline
\end{tabular}

\section{EXPERIMENTS AND EVALUATION}

\section{A. Outline of Experiments}

There are 2 experiments. In Experiment 1, first, for four pieces of music, K.331, Sonata Pathétique, Träumerei, and Étude, the multiple regression analysis is done and the partial regression coefficients of independent variables, i.e. the existence of each expression marks, and also, the tension and attraction, are obtained, for every performance for every pianists, individually. Second, the averages and the significances of each coefficient by $D$ and $U$, for each piece, are calculated. Each average of coefficients of independent variables shows the tendency of the corresponding performance. By comparing and 
evaluating them, some significant differences of performances between distinguished and unnamed pianists are obtained.

In Experiment 2, the two pieces, K.331 and Sonata Pathétique, are subjects to the experiment. First, the "estimated" performances of these pieces by each pianist belonging to $D$ are created from the values of the partial coefficients of both tempo and volume obtained in Experiment 1. For K.331, 8 estimated performances for 8 pianists are obtained, whereas 3 performances are created for Sonata Pathétique from the performances by 3 pianists. From the averages of the coefficients of tempo and volume from all performances by $U$, the estimated performances of these two pieces performed by them are also obtained. In order to compare them, the correlation coefficients between each estimated performances of $D$ and that of $U$ are calculated.

\section{B. The Results of Experiments}

Tables 2 and 3 show the results of Experiment 1. The regression coefficients calculated for every performance data are in both tables. “_M” with the names of the independent variable means the corresponding independent variable is for the melody part, while "_A" for the accompaniment. NA indicates that the value is not significant, which is obtained from the p-value.

TABLE II. THE REGRESSION COEFFICIENT OF THE INDEPENDENT VARIABLES FOR TEMPO

\begin{tabular}{|c|c|c|}
\hline \multirow{2}{*}{$\begin{array}{l}\text { Independent } \\
\text { Variables }\end{array}$} & \multicolumn{2}{|c|}{ Average of Regression Coefficient } \\
\hline & $\begin{array}{c}\text { Distinguished } \\
\text { Pianists }\end{array}$ & $\begin{array}{c}\text { Unnamed } \\
\text { Pianists }\end{array}$ \\
\hline piano_start_M & -0.162 & -0.158 \\
\hline slur_start_M & NA & 0.0351 \\
\hline slur_cont_M & 0.0485 & 0.0505 \\
\hline slur_end_M & -0.0331 & -0.103 \\
\hline cre_end_M & -0.146 & NA \\
\hline decre_cont_M & 0.0968 & NA \\
\hline graced_M & -0.269 & NA \\
\hline slur_start_A & -0.0292 & -0.0557 \\
\hline slur_end_A & 0.0801 & -0.0594 \\
\hline cre_start_A & 0.194 & NA \\
\hline rit_start & NA & -0.337 \\
\hline rit_cont & -0.247 & NA \\
\hline rit_end & -0.440 & NA \\
\hline tension & 0.00319 & -0.0025 \\
\hline
\end{tabular}

TABLE III. THE REGRESSION COEFFICIENT OF THE INDEPENDENT VARIABLES FOR VOLUME

\begin{tabular}{|l|l|l|}
\hline \multirow{2}{*}{$\begin{array}{c}\text { Independent } \\
\text { Variables }\end{array}$} & \multicolumn{2}{|c|}{$\begin{array}{c}\text { Average of Regression Coefficient } \\
\text { Pianists }\end{array}$} \\
\cline { 2 - 3 } forte_start_M & 0.298 & $\begin{array}{c}\text { Unnamed } \\
\text { Pianists }\end{array}$ \\
\hline piano_start_M & NA & NA \\
\hline slur_start_M & NA & -0.112 \\
\hline slur_cont_M & NA & -0.103 \\
\hline slur_end_M & NA & -0.0533 \\
\hline decre_cont_M & -0.211 & -0.03502 \\
\hline pre_grace_M & -0.0612 & NA \\
\hline slur_start_A & NA & NA \\
\hline slur_end_A & -0.0894 & 0.0691 \\
\hline cre_start_A & 0.254 & NA \\
\hline cre_cont_A & 0.142 & NA \\
\hline pedal_on & 0.00880 & NA \\
\hline tension & 0.00319 & NA \\
\hline attraction & 0.0130 & 0.00671 \\
\hline
\end{tabular}

Tables 4 and 5 show the results of Experiment 2. The comparison of tempo and volume of the estimated performances of K.331 of the distinguished pianists with the average of those of the unnamed ones, whose performances are obtained from the values of the partial regression coefficients appears in Table 4, while Tables 5 shows those of Sonata Pathétique.

TABLE IV. COMPARISON FOR K.331

\begin{tabular}{|c|c|c|}
\hline \multirow{2}{*}{$\begin{array}{l}\text { Name of } \\
\text { Pianists }\end{array}$} & \multicolumn{2}{|c|}{ Correlation Coefficient } \\
\hline & Tempo & Volume \\
\hline Eschenbach & 0.587763 & 0.479137 \\
\hline Gould & 0.330775 & 0.114624 \\
\hline Haebler & 0.58485 & 0.513128 \\
\hline Kraus & 0.442624 & 0.426732 \\
\hline deLarrocha & 0.492435 & 0.502733 \\
\hline Nakamura & 0.225751 & 0.020153 \\
\hline Pires & 0.462745 & 0.602624 \\
\hline Shimizu & 0.350253 & 0.740088 \\
\hline
\end{tabular}


TABLE V. COMPARISON FOR SONATA PATHÉTIQUE

\begin{tabular}{|l|l|l|}
\hline \multirow{2}{*}{$\begin{array}{c}\text { Name of } \\
\text { Pianists }\end{array}$} & \multicolumn{2}{|c|}{ Correlation Coefficient } \\
\cline { 2 - 3 } & \multicolumn{1}{|c|}{ Tempo } & \multicolumn{1}{c|}{ Volume } \\
\hline Arrau & 0.396562 & 0.531891 \\
\hline Ashkenazy & 0.307009 & 0.421104 \\
\hline Backhaus & 0.382004 & 0.236953 \\
\hline
\end{tabular}

\section{Evaluation}

From the results of Experiment 1, some notable facts are obtained. (i) As shown in Table 2, the musical factors affecting tempo of the performances played by the pianists in $D$ are piano, slur, ritardando, tonal tension, crescendo, decrescendo and grace notes, whereas crescendo, decrescendo and grace notes do not affect tempo by the pianists in $U$. (ii) Although crescendo and decrescendo are expression marks for volume, not for tempo, each of which means volume is increased, and decreased gradually, respectively, the expression of tempo played by the pianists in $D$ are affected by these marks. Namely, the pianists in $D$ play slowly when they play at the end of crescendo and play quickly during decrescendo. The pianists in $U$ do not play like them. (iii) Table 3 shows that the musical factors affecting volume of the performances by $D$ and $U$ are exclusive with each other, except for tension and attraction. Especially, the pianists in $D$ are not affected by piano (to play softly) for volume. (iv) Tension affects both tempo and volume significantly, while attraction affects significantly only volume, in both performances by $D$ and $U$.

From the Experiment 2, it is shown that every performance of K.331 and Sonata Pathétique by pianist in $D$ is not similar to that by $U$. For K.331, the performance by Ingrid Haebler is rather similar to the average performance by $U$. Since she is one of the famous pianists for Mozart, it may be conjectured that most amateur or semi-professional pianists would follow her performances when they play pieces by Mozart.

\section{RELATED WORKS}

There are many researches in this area. Especially, a system for the multiple regression analysis in order to apply the musical expression has been developed [9]. However, there are few researches that investigate the relationship between musical expression and the tonal tension and attraction models introduced in TPS. In [10], musical tension is analyzed by the empirical data obtained by many examinees who listen musical performances and answer the tension points in real time. From these analyses, a kind of perception and predictive models of tension are introduced.

\section{SUMMARY}

From analyses of the musical expression by distinguished and unnamed pianists, some specific results are obtained, i.e. the difference between the musical expression by the distinguished pianists and that by unnamed pianists is very definite. Especially, the number of the musical factors affecting the performances significantly by the distinguished pianists is more than those by the unnamed ones. And moreover, some expression marks, i.e. crescendo, decrescendo and piano do not affect as an intuitive meaning, for the distinguished pianists.

There are many future works that the authors must done. For example, more pieces and performance data will be analyzed, more musical factors will be introduced as the independent variables, more precise statistical analyses will be done, and so on. Additionally, the performances by the unnamed pianists will be grouped under several classifications, e.g. who is the most similar distinguished pianists to each unnamed one. And moreover, a program system creating artistic performances automatically will be implemented.

\section{REFERENCES}

[1] F. Lerdahl and R. Jackendoff, A Generative Theory of Tonal Music, The MIT Press, Cambridge, 1983.

[2] F. Lerdahl, Tonal Pitch Space, Oxford University Press, Oxford, 2001.

[3] T. Mizutani and Y. Iwami, “A musical expression model using tonal tension”, Proceedings of the 2016 International Conference on Computational Modeling, Simulation and Applied Mathematics (CMSAM 2016), 2016, pp. 220-224.

[4] Y. Iwami, Analysis of Musical Expression using Tonal Tension and Attraction Models, Master's Thesis, Department of Computer Science, Graduate School of System and Information Engineering, University of Tsukuba, 2017, in Japanese.

[5] T. Mizutani and Y. Iwami, "Analysis of musical expression using tonal tension and attraction models”, 2017 2nd International Conference on Applied Mathematics, Simulation and Modelling (AMSM 2017), 2017, pp. 344-348.

[6] S. Nakahara, Analysis of Musical Expression of Amatuer Pianists using Tonal Tension and Attraction Models, Graduation Thesis, College of Information Science, University of Tsukuba, 2018, in Japanese.

[7] A. Sen and M. Srivastava, Regression Analysis - Theory, Methods, and Applications, Springer-Verlag, Berlin, 2011 (4th printing).

[8] CrestMusePEDB, [Online]. Available: http://www.crestmuse.jp/pedb/. [Accessed 05 May. 2018].

[9] O. Ishikawa, H. Katayose and S. Inokuchi, "Identification of music performance rules based on iterated multiple regression analysis”, J. Information Processing, vol. 43, 2002, pp. 268-275 (in Japanese).

[10] M. M. Farbood, “A global model of musical tension”, Proceedings of the 10th International Conference on Music Perception and Cognition (ICMPC10), 2008, pp. 690-695. 